\title{
Effect of Aromatic SAMs Molecules on Graphene/Silicon Schottky Diode Performance
} \author{
and Y. Selamet ${ }^{\mathrm{a}, \mathrm{d}}$ \\ ${ }^{a}$ Material Science and Engineering, Izmir Institute of Technology, Izmir, Turkey \\ ${ }^{b}$ Department of Engineering Sciences, Izmir Kâtip Çelebi University, Izmir, Turkey \\ ${ }^{c}$ Department of Electrical and Electronics, Ege University, Izmir, Turkey \\ ${ }^{d}$ Department of Physics, Izmir Institute of Technology, Izmir, Turkey
}

N. Yagmurcukardes, ${ }^{\mathrm{a}, \mathrm{z}}$ H. Aydın, ${ }^{\mathrm{a}, \mathrm{z}}$ M. Can, ${ }^{\mathrm{b}}$ A. Yanılmaz, ${ }^{\mathrm{a}}$ Ö. Mermer, ${ }^{\mathrm{c}}$ S. Okur, ${ }^{\mathrm{b}}$

\begin{abstract}
$\mathrm{Au} / \mathrm{n}-\mathrm{Si} / \mathrm{Graphene/Au} \mathrm{Schottky} \mathrm{diodes} \mathrm{were} \mathrm{fabricated} \mathrm{by} \mathrm{transferring} \mathrm{atmospheric} \mathrm{pressure} \mathrm{chemical} \mathrm{vapor} \mathrm{deposited} \mathrm{(APCVD)}$ graphene on silicon substrates. Graphene/n-Si interface properties were improved by using 5-[(3-methylphenyl)(phenyl) amino]isophthalic acid (MePIFA) and 5-(diphenyl)amino]isophthalic acid (DPIFA) aromatic self-assembled monolayer (SAM) molecules. The surface morphologies of modified and non-modified films were investigated by atomic force microscopy and scanning electron microscopy. The surface potential characteristics were obtained by Kelvin-probe force microscopy and found as $0.158 \mathrm{~V}, 0.188 \mathrm{~V}$ and $0,383 \mathrm{~V}$ as a result of SAMs modification. The ideality factors of n-Si/Graphene, n-Si/MePIFA/Graphene and $\mathrm{n}$-Si/DPIFA/Graphene diodes were found as 1.07, 1.13 and 1.15, respectively. Due to the chain length of aromatic organic MePIFA and DPIFA molecules, also the barrier height $\phi_{\mathrm{B}}$ values of the devices were decreased. While the barrier height of $\mathrm{n}-\mathrm{Si} / \mathrm{Graphene}$ diode was obtained as $0.931 \mathrm{eV}$, n-Si/MePIFA/Graphene and n-Si/DPIFA/Graphene diodes have barrier height of 0.820 and 0.720 $\mathrm{eV}$, respectively.
\end{abstract}

(C) 2016 The Electrochemical Society. [DOI: 10.1149/2.0141607jss] All rights reserved.

Manuscript submitted April 20, 2016; revised manuscript received May 20, 2016. Published May 31, 2016.

Graphene is a one-atom thick sheet of $\mathrm{sp}^{2}$ bonded carbon atoms that are arranged in a honeycomb crystal lattice with exceptional properties. At room temperature electron mobility reached $2.5 \times$ $10^{5} \mathrm{~cm}^{2} /$ V.s. ${ }^{1}$ Young's modulus of $1 \mathrm{TPa}$ and intrinsic strength of $130 \mathrm{GPa}$ are very close to that were predicted by theory. ${ }^{2}$ Very high thermal conductivity (above $3000 \mathrm{WmK}^{-1}$ ), ${ }^{3}$ low optical absorption $(\sim 2.3 \%),{ }^{4}$ ability to sustain high electric current densities ${ }^{5}$ and be suitable to chemical functionalization ${ }^{6-8}$ are other important properties of graphene that attract great attention. When graphene is transferred onto semiconductors such as $\mathrm{GaAs}, \mathrm{GaN}, \mathrm{SiC}$ and $\mathrm{Si}$; it forms Schottky junctions. ${ }^{9-12}$ More efficient and stable solar cells and Schottky barrier devices will be achieved by the development of surface improvement, doping and functionalization. ${ }^{13,14}$ The electrical transport performance of the fabricated Schottky diode is directly based on interface properties between substrate and graphene layer. ${ }^{15}$

Chemical Vapor Deposition (CVD) is promising technique for large area and high quality graphene growth. ${ }^{16}$ In this technique, carbon precursors (methane, ethylene) are deposited carbon atoms onto the surfaces of various transition metals such as Nickel and Copper under high temperatures and form graphene. ${ }^{16-18}$

Self-assembled monolayers (SAMs) are well-oriented molecular structures that are formed by the adsorption of an active surfactant on a substrate surface. Aromatic SAMs were used to modify anode/hole transport layer interface in order to achieve preferable barrier alignment and charge carrier injection. ${ }^{19,20}$ Additionally, SAM modification of graphene also leads to electronic passivation of graphene edges and defects, thus might be responsible for a strong doping at the interface due to high acidity of the protons. ${ }^{21}$ Although there have been various studies to enhance Schottky diodes depend on the graphene layers, researches on SAMs modification of silicon and graphene interface has been insufficient.

In this study, n-type silicon substrates were modified by novel MePIFA and DPIFA SAM molecules to improve grafene/Si interface properties and increase charge carrier injection. Schottky diodes were fabricated by CVD grown graphene layers that were transferred onto bare and SAMs modified n-type silicon substrates. Electronic characteristics of the diodes were investigated by forward bias current-voltage measurements at room temperature. Atomic Force Microscopy (AFM) and Kelvin Probe Force Microscopy (KPFM) techniques were used to obtain surface morphology and surface potential properties of the bare and SAM modified film surfaces.

\section{Experimental}

Preparation of SAM molecules.-5-[(3-methylphenyl)(phenyl) amino]isophthalic acid (MePIFA) and 5-(diphenyl)amino]isophthalic acid (DPIFA) aromatic small molecules with double bond carboxylic acid were used as self-assembly monolayers (SAMs) (see Figure 1). The synthesis procedure of SAM molecules was reported in our previous study. ${ }^{22}$ SAM molecules with $1 \mathrm{mM}$ concentration were prepared at room temperature in methanol solution. $\mathrm{SiO}_{2}(300 \mathrm{~nm}) / \mathrm{n}-\mathrm{Si}$ substrates were kept in methanol-SAM solution for 24 hours to be covered with MePIFA and DPIFA SAM molecules. The substrates were then rinsed with methanol to remove SAM molecules residues.

Graphene growth and transfer process.- $\mathrm{Cu}$ foil $(25 \mu \mathrm{m}$ thick, 99.8\% purity, Alfa Aesar) was used as catalyst-substrate material which on a quartz glass placed in the atmospheric pressure CVD system. First of all, the $\mathrm{Cu}$ foil was heated up to $1073^{\circ} \mathrm{C}$ under $\mathrm{H}_{2}$ $(20 \mathrm{sccm})$ and $\operatorname{Ar}(200 \mathrm{sccm})$ with a ramp $30^{\circ} \mathrm{C} \mathrm{m^{-1 }}$ then annealed under same temperature and flows for a one hour. After annealing, $\mathrm{CH}_{4}(10 \mathrm{sccm})$ was introduced in tube furnace for three minutes in order to obtain graphene growth. Finally, sample was left for rapid cooling down to the room temperature in a gas flows of $\mathrm{H}_{2}(20 \mathrm{sccm})$ and $\operatorname{Ar}(200 \mathrm{sccm})$.

Microposit S1318 Photoresist (PR) was utilized as supporting layer during the graphene transfer process. We drop casted on the graphene$\mathrm{Cu}$ substrate and waited overnight at $70^{\circ} \mathrm{C}$. Iron Chloride $\left(\mathrm{FeCl}_{3}\right)$ was used for $\mathrm{Cu}$ etching. As the $\mathrm{Cu}$ foil fully etched away, graphene-PR

(a)<smiles>Cc1cccc(N(c2ccccc2)c2cc(C(=O)O)cc(C(=O)O)c2)c1</smiles>

MePIFA (b)<smiles>O=C(O)c1cc(C(=O)O)cc(N(c2ccccc2)c2ccccc2)c1</smiles>

DPIFA 

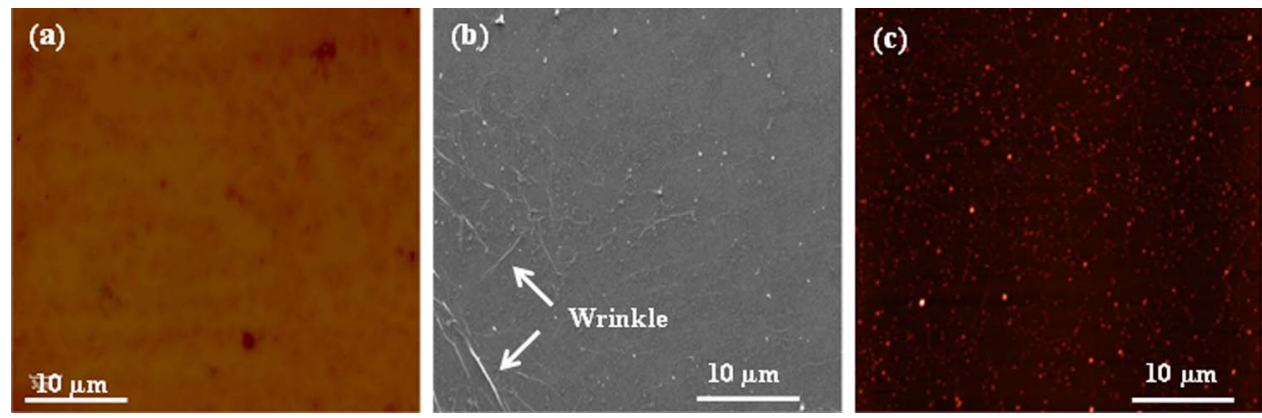

Figure 2. Surface morphology characteristic of graphene transferred on $\mathrm{SiO}_{2} / \mathrm{Si}$. (a) Optical Microscope b) SEM micrograph and (c) AFM image.

was cleaned by DI water to remove $\mathrm{FeCl}_{3}$ residue. After $\mathrm{N}_{2}$ drying, graphene-PR was transferred to clean $\mathrm{SAMs} / \mathrm{SiO}_{2} / \mathrm{n}-\mathrm{Si}(0.01-30 \Omega$ $\mathrm{cm})$ substrate and bare $\mathrm{SiO}_{2} / \mathrm{n}-\mathrm{Si}$ substrate. Thereafter, substrates were baked at $110^{\circ} \mathrm{C}$ in order to provide better adhesion of graphene to the substrates. Finally, PR was removed in hot acetone to yield large area graphene on $\mathrm{SAMs} / \mathrm{SiO}_{2} / \mathrm{n}-\mathrm{Si}$ and $\mathrm{SiO}_{2} / \mathrm{n}-\mathrm{Si}$ substrate.

Device fabrication and characterization.-We etched a part of $\mathrm{SiO}_{2}$ to prevent electrical shortening along the graphene layer. Then, transferred graphene placed on etch $\mathrm{SiO}_{2} / \mathrm{n}-\mathrm{Si}$ substrate. Finally, gold with a thickness of $100 \mathrm{~nm}$ was deposited as front and back contact (area $=1 \mathrm{~mm}$ ) using thermal evaporation technique.

Raman Spectroscopy of transferred graphene was performed using Ar-ion gas laser operating at $488 \mathrm{~nm}$ wavelength with 600 groove $/ \mathrm{mm}$ grating under $100 \times$ microscope objective. Sheet resistance of transferred graphene on $\mathrm{SiO}_{2}(300 \mathrm{~nm}) / \mathrm{Si}$ was measured using Van der Pauw's method. Current-Voltage characteristic of modified SAM molecules $\mathrm{SiO}_{2}(300 \mathrm{~nm}) / \mathrm{n}-\mathrm{Si}$ and bare one device were taken with two probe measurement via 2420 SourceMeter under dark condition. Atomic Force Microscopy (AFM) and Kelvin Probe Force Microscopy (KPFM) were performed using TiN cantilever with curvature radius of $35 \mathrm{~nm}$ (NTMDT).

\section{Results and Discussion}

Surface characterization.-Figure 2a shows difference color contrast in optical image due to inhomogeneity fully coverage graphene films on $\mathrm{SiO}_{2 /} \mathrm{Si}$ substrate. SEM image of graphene transferred on $\mathrm{SiO}_{2 /} \mathrm{Si}$ substrate as indicated in Figure $2 \mathrm{~b}$. Some wrinkle was observed owing to the difference thermal expansion coefficient between $\mathrm{Cu}$ surface and graphene film during the cooling. As seen from Figure 2c, small particles are believed to be $\mathrm{SiO}_{2}$ were observed in the AFM image, as reported in similar works. ${ }^{23,24}$ The formation of $\mathrm{SiO}_{2}$ can be observed because the Si particles from CVD react with oxygen in APCVD condition. Therefore, they could be probably transferred with graphene on $\mathrm{SiO}_{2 /} \mathrm{Si}$.

Raman spectrum indicates typical appearance of transferred graphene on $\mathrm{SiO}_{2} / \mathrm{Si}$ including D band $\left(1369 \mathrm{~cm}^{-1}\right), \mathrm{G}\left(1587 \mathrm{~cm}^{-1}\right)$ and $\mathrm{G}^{\prime}$ band $\left(2726 \mathrm{~cm}^{-1}\right)$ respectively (see Figure $3 \mathrm{a}$ ). The $\mathrm{G}$ band is the first Raman peak related to C-C stretching of $\mathrm{sp}^{2}$ carbon. The $\mathrm{G}^{\prime}$ band is the second order graphene peak and the D provides information about the $\mathrm{sp}^{3}$ bonds revealing "amount of disorder" in graphene. In addition to this, Intensity ratio of $G / G^{\prime}$ and $D / G$ have been utilized to identify number of graphene layers and defect content of graphene. $\mathrm{I}_{\mathrm{G}^{\prime} / \mathrm{G}}$ and $\mathrm{I}_{\mathrm{D} / \mathrm{G}}$ were about 0.97 and 0.08 verifying presence of high quality bilayer graphene..$^{25-27}$

The $\mathrm{G}^{\prime}$ in bilayer can be deconvoluted in more components due to four possible scattering process as shown in Figure $3 \mathrm{~b}$. The bilayer graphene on $\mathrm{SiO}_{2} / \mathrm{Si}$ was confirmed by asymmetric $\mathrm{G}$ ' band with the full width half maximum (FWHM) of $48 \mathrm{~cm}^{-12} .8$

Sheet resistance measurement of transferred graphene on $\mathrm{SiO}_{2} / \mathrm{n}$ Si was performed using van der Pauw's method to investigate quality of the graphene. In this method, while the current was measured on two isolated contacts, the voltage is determined on opposing two contacts. ${ }^{29}$ Eight measurements were performed around sample and the calculated sheet resistance of graphene was about $298 \Omega /$ sq. This value is in good agreement for CVD grown bilayer graphene as reported in literature. ${ }^{26,30}$

As a next step, In order to understand modification of n-Si surface with DPIFA and MePIFA SAMs molecules, KPFM measurements were obtained using conductive AFM tip. The surface potential difference (SPD) between tip and sample can be define as follows: ${ }^{31}$

$$
V_{S P D}=\frac{\varphi_{\text {sample }}-\varphi_{t i p}}{e}
$$
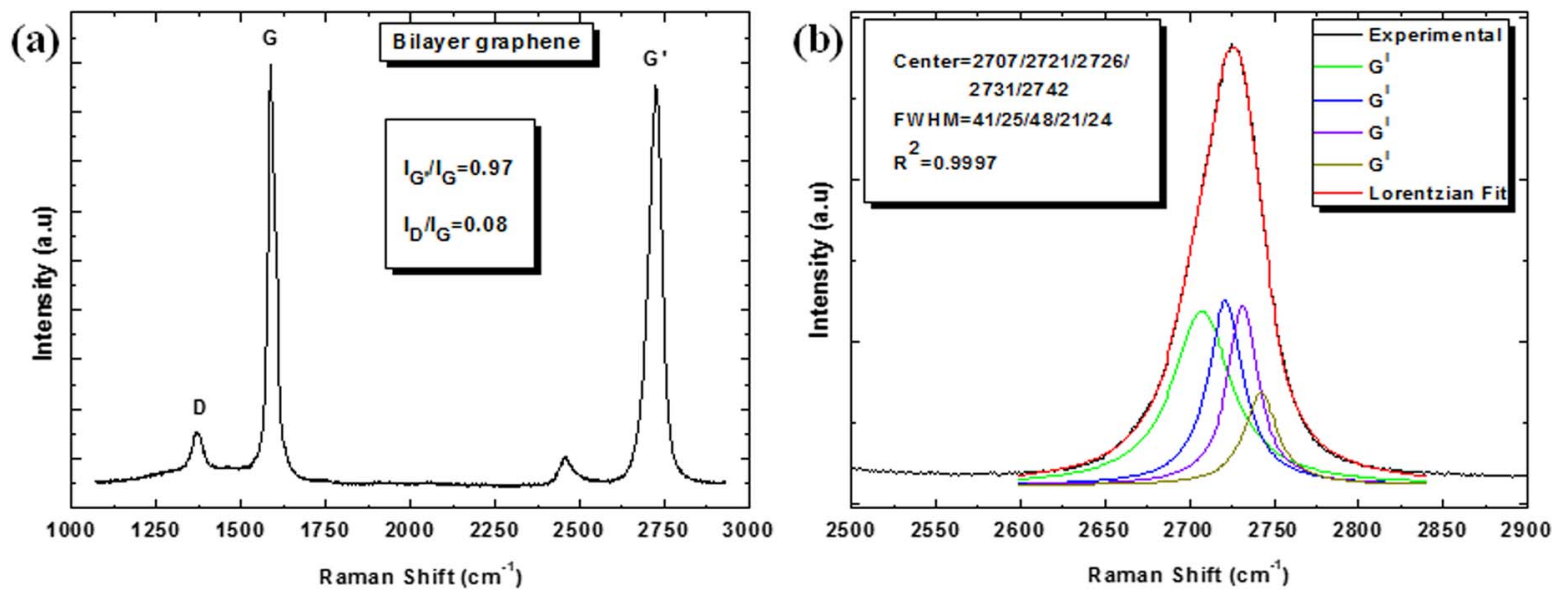

Figure 3. (a) Raman Spectrum of bilayer graphene transferred on $\mathrm{SiO}_{2} / \mathrm{Si}$ and (b) $\mathrm{G}^{\prime}$ band Raman spectrum of graphene fitted four Lorentzian peaks. 


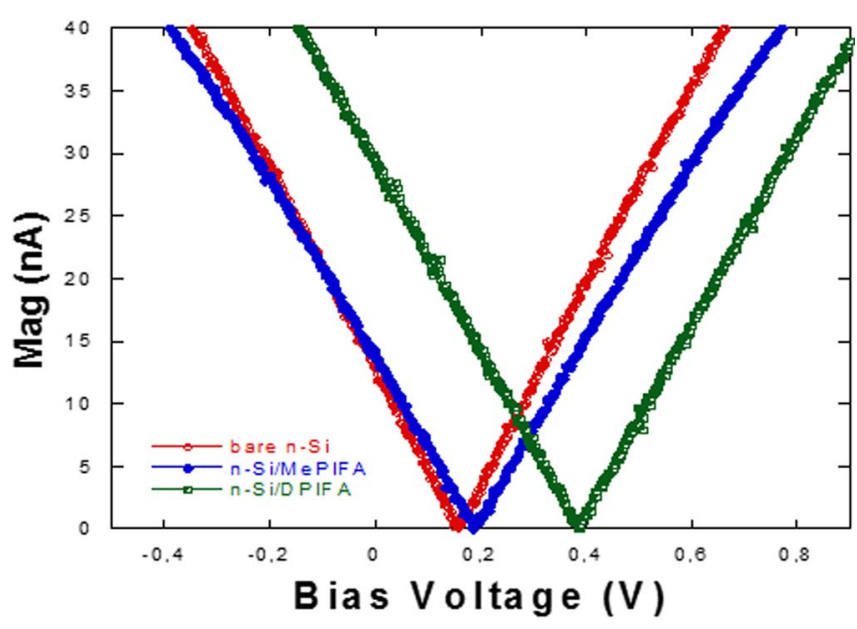

Figure 4. Contact potential differences of bare $\mathrm{n}-\mathrm{Si}$ and modified n-Si with MePIFA and DPIFA SAMs.

where e is the electric charge, $\varphi_{\text {sample }}$ and $\varphi_{\text {tip }}$ are the work functions of the sample, and TiN tip respectively. According to above equation, it is possible to obtain surface potential in terms of eV defined work functions of bare $\mathrm{n}-\mathrm{Si}$ and modified $\mathrm{n}-\mathrm{Si}$ with $\mathrm{SAMs}$ molecules. Figure 4 indicates cantilever oscillation amplitude (Mag) as a function of bias voltage. Bare $\mathrm{n}-\mathrm{Si}, \mathrm{n}$-Si/MePIFA and n-Si/DPIFA were measured as $0.158 \mathrm{~V}, 0.188 \mathrm{~V}$ and $0,383 \mathrm{~V}$ respectively. The differences of surface potential reveal the modification of n-Si surface with MePIFA and DPIFA SAMs molecular films. Increasing surface potential is related to enhanced charge density on the n-Si surface. In presence of the SAM molecules, potential distributions were enhanced compare to bare $\mathrm{n}$-Si surface. As a result, surface potentials of SAM modified $\mathrm{n}$-Si surfaces were increased with respect to the bare n-Si surface.

The current-voltage behavior of schottky diodes.-Device structures of bare and modified GRP/n-Si and bonding mechanism between double bond carboxylic acid based SAMs and n-Si with native oxide as illustrated in Figure 5a. Due to formation of ester bond on the surface, charge injection and transport occur through molecules and are enhanced owing to inelastic tunneling mechanism over its $\pi$-conjugated structure. ${ }^{32}$ Figure $5 \mathrm{~b}$ indicates schematic energy band diagram of $\mathrm{GRP} / \mathrm{n}-\mathrm{Si}$ junction. The work function differences between $\mathrm{n}-\mathrm{Si}$ and graphene lead to charge transfer from n-Si to graphene until alignment of Fermi level across the junction and as a result, bending of energy levels near junction take place. In the presence of SAMs molecules as shown in Figure 5c, molecular dipole layer created between n-Si and graphene and charge transfer are facilitated due to reduction of energy barriers and $\pi$-bonding between aromatic SAMs molecules and graphene. Under the applied electric field, electron transfer occurs from the donor SAM molecules to n- type silicon, resulting SAM molecules acts as a p-type dopant. Then, holes transfer is facilitated from SAM molecules to graphene due to $\pi-\pi$ interaction. As a result,

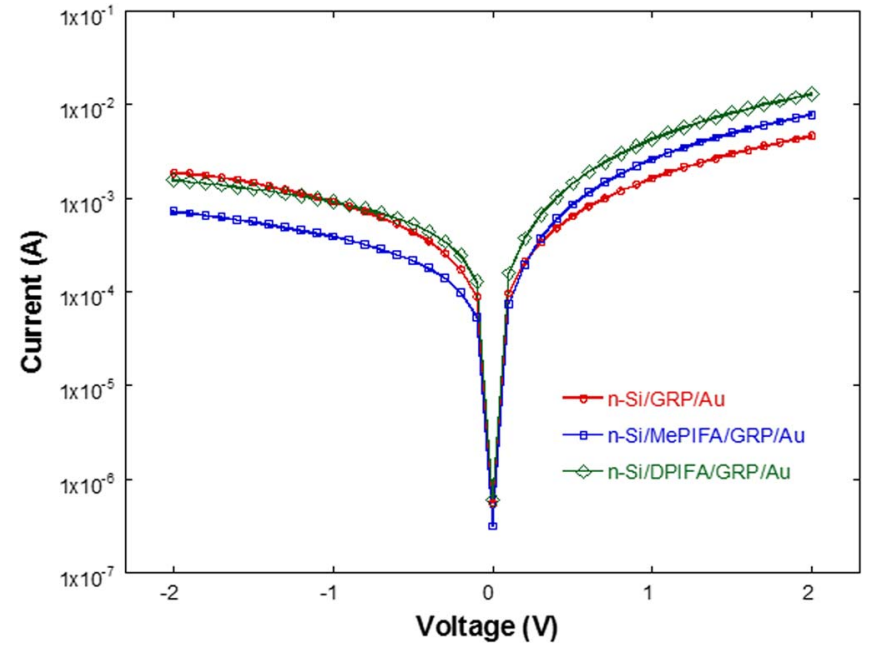

Figure 6. Current-voltage characteristics of the n-Si/GRP/Au, n$\mathrm{Si} / \mathrm{MePIFA} / \mathrm{GRP} / \mathrm{Au}$ and n-Si/DPIFA/GRP/Au diodes.

typically p-n junction is created. That's why we used n-type silicon to form $\mathrm{p}-\mathrm{n}$ junction.

The electronic parameters of constructed three devices were showed rectifying behavior like metal/ semiconductor Schottky contact. The current-voltage characteristics of $\mathrm{Au} / \mathrm{GRP} / \mathrm{n}-\mathrm{Si}$, $\mathrm{Au} / \mathrm{GRP} / \mathrm{MePIFA} / \mathrm{n}-\mathrm{Si}$ and Au/GRP/DPIFA/n-Si diodes were shown in Figure 6.

The diodes that modified by MePIFA and DPIFA SAM molecules were showed better rectifying behavior when compared to bare graphene based diode. At temperatures above $260 \mathrm{~K}$, current-voltage behavior can be analyzed by thermionic emission as, ${ }^{33}$

$$
I=A A^{*} T^{2} \exp \left(-\frac{q \phi_{B}}{k T}\right)\left[\exp \left(\frac{q V}{n k T}\right)-1\right]
$$

where $A$ is the effective contact area, $A^{*}$ is the Richardson constant, $T$ is the absolute temperature, $\phi_{B}$ is the barrier height, $k$ Boltzmann constant, $q$ is the electronic charge and $n$ is the ideality factor. Due to the value ideality factor was obtained as higher than unity, the effect of series resistance $\left(R_{s}\right)$ should be included and relation can be rewritten as, ${ }^{34}$

$$
\begin{aligned}
I= & A A^{*} T^{2} \exp \left(-\frac{q \phi_{B}}{k T}\right) \exp \left(\frac{q\left(V-I R_{s}\right)}{n k T}\right) \text { for } \\
& q\left(V-I R_{s}\right)>k T
\end{aligned}
$$

If Eq. 3 is rearranged;

$$
V=n \frac{k T}{q} \ln \left(\frac{I}{A A^{*} T^{2}}\right)+I R_{s}+n \phi_{B}
$$

When Eq. 4 is differentiated with respect to $I$,

$$
\frac{d V}{d \ln (I)}=n \frac{k T}{q}+I R_{s}
$$

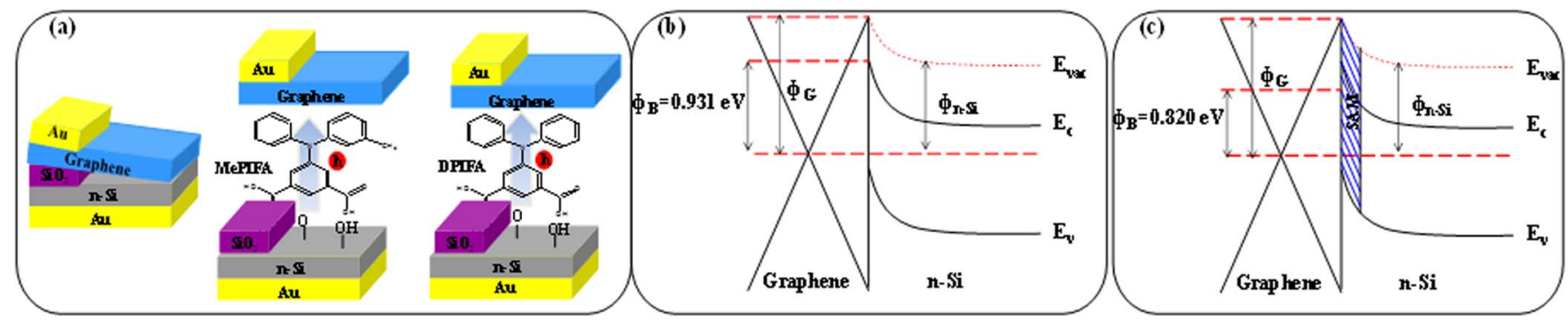

Figure 5. (a) Device structure of Au/n-Si/Grp/Au and Au/n-Si/SAMs/Grp/Au. Energy band diagram of (b) Grp/n-Si and (c) Grp/SAMs/n-Si junction. 
Table I. Electrical parameters of the Schottky diodes and surface potential values of bare and modified n-Si.

$\begin{array}{ccccc} & \mathrm{n} \text { (ideality factor) } & \Phi_{\mathrm{B}}(\mathrm{eV}) \text { (barrier height) } & \text { Surface Potential }(\mathrm{V}) & d V / d l n I \\ \mathrm{R}_{\mathrm{s}}(\Omega) & 0.158 & 301 \\ \text { n-Si/GRP } & 1.068 & 0.931 & 0.188 & 333.15 \\ \text { n-Si/MePIFA/GRP } & 1.133 & 0.820 & 0.383 & 208.40 \\ \text { n-Si/DPIFA/GRP } & 1.152 & 0.720 & 144.82\end{array}$

And function $H(I)$ is defined as;

$$
H(I)=V-n \frac{k T}{q} \ln \left(\frac{I}{A A^{*} T^{2}}\right)=I R_{s}+n \phi_{B}
$$

where $I$ is the saturation current. $d V / d \ln (I)$ vs. $I$ and $H(I)$ vs. $I$ plots for the diodes are shown in Figure 7 and electrical parameters that are calculated from these plots are presented in Table I.

Series resistance $\left(\mathrm{R}_{\mathrm{s}}\right)$ provides information about interface properties between graphene and $\mathrm{n}-\mathrm{Si}$. Values of the series resistance were calculated from both of the slope of the $d V / d \ln (I)$ vs. $I$ and $H(I)$ vs. $I$ plots and it is decreased with the SAMs surface improvement. In the presence of SAM molecule, incompatible surface between graphene and $\mathrm{n}-\mathrm{Si}$ is decreased. Therefore, charge transfer is improved owing to due to $\pi-\pi$ interaction, leading to lower resistance at the interface. In addition, while the ideality factor $(n)$ that was calculated from the intercept of the $d V / d \ln (I)$ vs. ot of the SAM included devices are higher than that of bare graphene diodes, barrier height decreased from $0.931 \mathrm{eV}$ to $0.720 \mathrm{eV}$ with DPIFA and MePIFA surface modification of silicon surface due to compatible interface between graphene and n-Si. Diode with DPIFA SAMs showed better characteristic than that of diode modified by MEPIFA SAMs because, MEPIFA SAMs
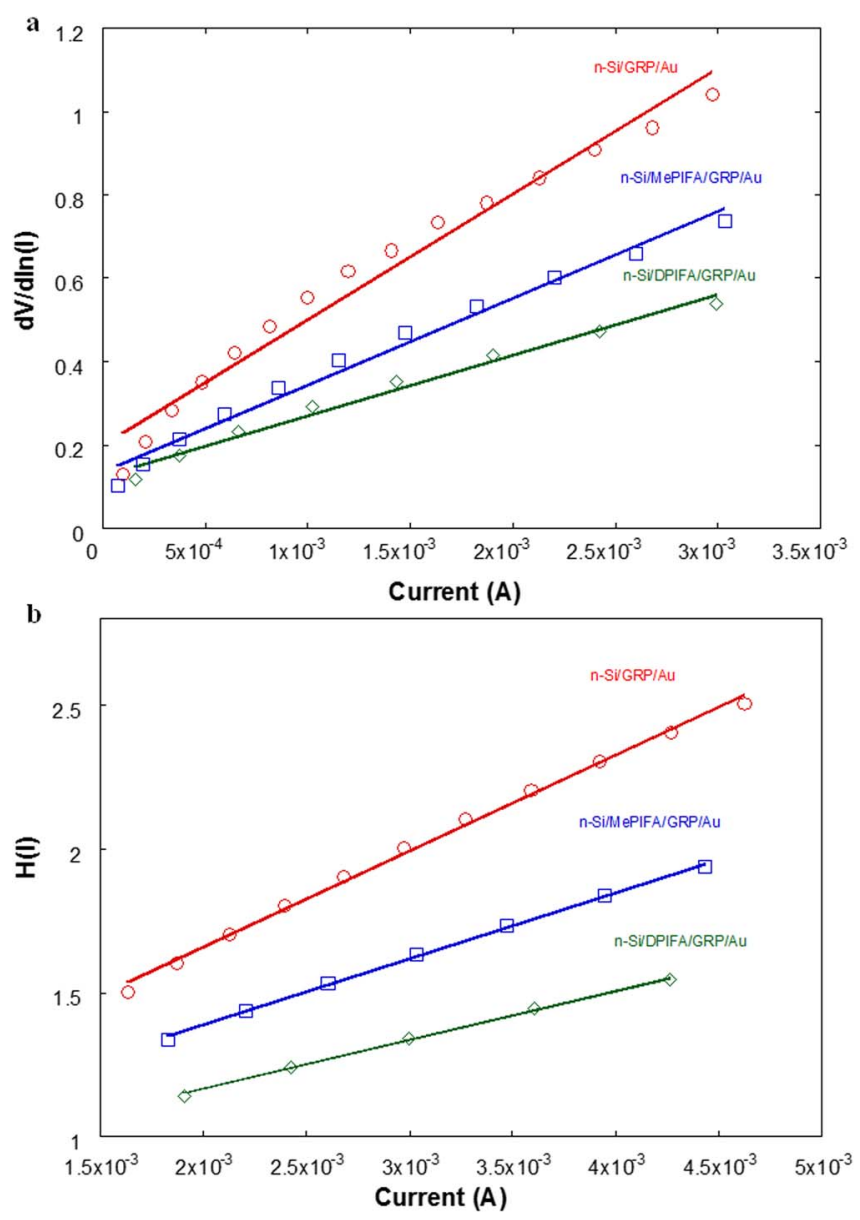

Figure 7. $\boldsymbol{d} \boldsymbol{V} / \boldsymbol{d} \boldsymbol{l n}(\boldsymbol{I})$ vs. $\boldsymbol{I}$ and $\boldsymbol{H}(\boldsymbol{I})$ vs. $\boldsymbol{I}$ plots of the n-Si/GRP/Au, n$\mathrm{Si} / \mathrm{MePIFA} / \mathrm{GRP} / \mathrm{Au}$ and $\mathrm{n}$-Si/DPIFA/GRP/Au diodes. molecule includes methyl groups restricting $\pi-\pi$ interaction between SAMs and graphene and has longer chain lengths. These limitations of $\pi-\pi$ interaction and extra chain length obstruct charge transfer when compared to DPIFA molecules and thus, diode with DPIFA molecule has lower barrier height and series resistance value (Table I).

\section{Conclusions}

In summary, we investigated electrical characterization of bare and SAMs modified CVD grown graphene/n-Si Shottky diodes. MePIFA and DPIFA molecules were used as SAMs to improve graphene/nSi substrate interface properties. KPFM technique was performed to define surface potential differences of bare and SAMs modified n-Si. The increments of surface potentials in SAMs modified n-Si cause to reduce energy barrier between aromatic SAMs and graphene with respect to the bare device. Raman spectroscopy and sheet resistance measurement of transferred graphene on $\mathrm{SiO}_{2} / \mathrm{Si}$ confirmed the presence of the high quality bilayer graphene. The I-V characteristics of bare and SAMs modified graphene/n-type silicon interfaces showed Schottky barrier and rectifying behavior. Additionally, DPIFA SAMs exhibit better diode characteristic compare to MePIFA SAMs due to not containing methyl group which hinders $\pi-\pi$ interaction between SAMs molecule and graphene. Finally, while the ideality factor values increase with modification, barrier height and series resistance values decreased indicating higher diode performance.

\section{Acknowledgments}

This work was supported by TUBITAK (The Scientific and Technical Research Council of Turkey) with project number 112T946. We also thank AQuReC (Applied Quantum Research Center) for Raman measurements.

\section{References}

1. A. S. Mayorov, R. V. Gorbachev, S. V. Morozov, L. Britnell, R. Jalil, L. A. Ponomarenko, P. Blake, K. S. Novoselov, K. Watanabe, and T. Taniguchi, Nano letters, 11, 2396 (2011).

2. C. Lee, X. Wei, J. W. Kysar, and J. Hone, science, 321, 385 (2008),

3. A. A. Balandin, Nature materials, 10, 569 (2011).

4. R. Nair, P. Blake, A. Grigorenko, K. Novoselov, T. Booth, T. Stauber, N. Peres, and A. Geim, Science, 320, 1308 (2008).

5. J. Moser, A. Barreiro, and A. Bachtold, Applied Physics Letters, 91, 163513 (2007).

6. D. Elias, R. Nair, T. Mohiuddin, S. Morozov, P. Blake, M. Halsall, A. Ferrari, D. Boukhvalov, M. Katsnelson, and A. Geim, Science, 323, 610 (2009).

7. K. P. Loh, Q. Bao, P. K. Ang, and J. Yang, Journal of Materials Chemistry, 20, 2277 (2010).

8. R. R. Nair, W. Ren, R. Jalil, I. Riaz, V. G. Kravets, L. Britnell, P. Blake, F. Schedin, A. S. Mayorov, and S. Yuan, Small, 6, 2877 (2010).

9. S. Tongay, M. Lemaitre, X. Miao, B. Gila, B. Appleton, and A. Hebard, Physical Review X, 2, 011002 (2012).

10. D. Sinha and J. U. Lee, Nano letters, 14, 4660 (2014).

11. D. Tomer, S. Rajput, L. Hudy, C. Li, and L. Li, Applied Physics Letters, 106, 173510 (2015).

12. C.-C. Chen, M. Aykol, C.-C. Chang, A. Levi, and S. B. Cronin, Nano letters, 11, 1863 (2011).

13. X. Li, H. Zhu, K. Wang, A. Cao, J. Wei, C. Li, Y. Jia, Z. Li, X. Li, and D. Wu, Advanced Materials, 22, 2743 (2010).

14. N.-W. Park, W.-Y. Lee, S.-K. Lee, D.-J. Kim, G.-S. Kim, J.-H. Hyung, C.-H. Hong, J.-H. Koh, and K.-S. Kim, Journal of the Korean Physical Society, 66, 22 (2015).

15. F. Nüesch, E. Forsythe, Q. Le, Y. Gao, and L. Rothberg, Journal of Applied Physics, 87, 7973 (2000)

16. A. Reina, X. Jia, J. Ho, D. Nezich, H. Son, V. Bulovic, M. S. Dresselhaus, and J. Kong, Nano letters, 9, 30 (2008).

17. K. S. Kim, Y. Zhao, H. Jang, S. Y. Lee, J. M. Kim, K. S. Kim, J.-H. Ahn, P. Kim, J.-Y. Choi, and B. H. Hong, Nature, 457, 706 (2009). 
18. M. P. Levendorf, C. S. Ruiz-Vargas, S. Garg, and J. Park, Nano letters, 9, 4479 (2009).

19. A. Havare, S. Okur, N. Yagmurcukardes, M. Can, H. Aydin, M. Seker, and S. Demic, Acta Physica Polonica, A, 123 (2013)

20. M. Yaman, N. Yagmurcukardes, A. K. Havare, H. Aydin, K. Ocakoglu, and S. Okur, Acta Physica Polonica A, 123, 459 (2013).

21. B. Lee, Y. Chen, F. Duerr, D. Mastrogiovanni, E. Garfunkel, E. Andrei, and V. Podzorov, Nano letters, 10, 2427 (2010)

22. M. Can, A. K. Havare, H. Aydın, N. Yagmurcukardes, S. Demic, S. Icli, and S. Okur, Applied Surface Science, 314, 1082 (2014).

23. D. H. Jung, C. Kang, M. Kim, H. Cheong, H. Lee, and J. S. Lee, The Journal of Physical Chemistry C, 118, 3574 (2014).

24. A. Ibrahim, S. Akhtar, M. Atieh, R. Karnik, and T. Laoui, Carbon, 94, 369 (2015).

25. K. Yan, H. Peng, Y. Zhou, H. Li, and Z. Liu, Nano letters, 11, 1106 (2011).

26. S. Chen, W. Cai, R. D. Piner, J. W. Suk, Y. Wu, Y. Ren, J. Kang, and R. S. Ruoff, Nano letters, 11, 3519 (2011).
27. Z. Yan, Z. Peng, Z. Sun, J. Yao, Y. Zhu, Z. Liu, P. M. Ajayan, and J. M. Tour, ACS nano, 5,8187 (2011).

28. D. Kim, J. Y. Han, D. Lee, Y. Lee, and D. Y. Jeon, Journal of Materials Chemistry, 22, 20026 (2012)

29. D. K. Schroder, Semiconductor material and device characterization; John Wiley \& Sons, 2006

30. M. Madito, A. Bello, J. Dangbegnon, C. Oliphant, W. Jordaan, D. Momodu, T. Masikhwa, F. Barzegar, M. Fabiane, and N. Manyala, Journal of Applied Physics, 119, 015306 (2016).

31. R. Kumar, D. Varandani, and B. Mehta, Carbon, 98, 41 (2016)

32. A. K. Havare, M. Can, S. Demic, S. Okur, M. Kus, H. Aydın, N. Yagmurcukardes, and S. Tari, Synthetic Metals, 161, 2397 (2011).

33. S. M. Sze and K. K. Ng, Physics of semiconductor devices; John Wiley \& Sons, 2006.

34. S. Cheung and N. Cheung, Applied Physics Letters, 49, 85 (1986). 